\title{
Las nuevas poblaciones de Sierra Morena bajo la superintendencia de don Pedro Pérez Valiente: oficios y colonos
}

\author{
Josefina Castilla Soto *
}

Las inquietudes de los ilustrados españoles del siglo XvIII se manifestaron a través de la realización de múltiples proyectos en diferentes campos y con resultados muy distintos. Uno de ellos fue, precisamente, la colonización de Sierra Morena en la que convergian múltiples objetivos. Por una parte, la despoblación en que se veía sumida la Península hacia necesaria una inmediata repoblación sobre todo con inmigrantes alemanes y franceses que pudieran ocupar huecos geográficos para hacerlos productivos. En este sentido, la repoblación de Sierra Morena no fue un caso aislado, sino uno más en la mente de teóricos y políticos empeñados en colonizar gran parte de España, en especial la zona occidental de Andalucía, Extremadura y Castilla '. Sierra Morena, sin embargo, marcó la pauta para repoblaciones simultáneas y posteriores en otros lugares.

Por otra parte, había un interés por garantizar la seguridad, a lo largo de una de las carreteras más peligrosas pero también más frecuentadas de las existentes en la red vial de lá época.

Sin embargo, desde nuestra óptica actual, lo que más nos llama la atención es ese intento por ensayar, en el marco de una sociedad propia del Antiguo Régimen, otra mucho más equitativa aunque no carente de marcados tintes idealistas. Se trataba, en definitiva, de prescindir de di-

\footnotetext{
* Profesora de Historia Moderna - UNED.

'Moran Martin, R., "Plan de repoblación en la segunda mitad del siglo Xvill y primera del siglo $x \mid x »$, Carlos III y las "Nuevas Poblaciones» (Actas del il Congreso-Histórico. La Carolina 1986), T. I. Córdoba 1988, pág. 256.
} 
ferencias de clases, manos muertas, provilegios de la Mesta, señorios y otros residuos del pasado, contra los que los ilustrados venían luchando con no mucho éxito"?

Asi una repoblación que Thurriegel y Olavide consideraron favorable para llevar a cabo en América, a base de seis mil colonos, se destinó finalmente para las áridas y estériles tierras de Sierra Morena contando, además, con la defensa a ultranza del proyecto por parte de don Pedro Rodríguez de Campomanes, fiscal del Consejo de Castilla.

El 5 de julio de 1767 se publicó el Fuero de las Nuevas Poblaciones ${ }^{3}$ y el 17 de agosto se inició la colonización propiamente dicha en el convento de La Peñuela. Por ello, los primeros colonos emigrados ocuparon las primeras suertes que estaban ubicadas en las inmediaciones del casco de la futura Carolina.

Según Alcázar Molina, los primeros tiempos de vida de las colonias fueron sumamente accidentados. La novedad del intento, las ideas reformadoras que entrañaban, los intereses creados, los escrúpulos de diversas órdenes, la intolerancia de las naciones y el apasionamiento de los extranjeros, influian en aquellos primeros años de conspiraciones y de luchas ${ }^{4}$.

Efectivamente, apenas transcurrido un año del inicio de la colonización, comenzaron a gestarse ya las primeras acusaciones hacia el gobierno de Olavide, acusaciones que Capel Margarito achaca, fundamentalmente, a los enemigos irreconciliables de Olavide, a los pueblos vecinos, a los mayorazgos que habían visto mermados sus tierra y baldíos y al temor que toda reforma social implica ${ }^{5}$. Especial resonancia tuvieron las acusaciones de Yauch, Mayor del cantón de Uri, quien elevó un memorial al rey, el 14 de marzo de 1769, sobre abusos y malos tratos dados a los pobladores extranjeros, en particular a las familias suizas. 428 .

Dominguez Ortiz, A., Sociedad y Estado en el siglo xwi español. Barcelona 1976, pág.

"Reglas para las Nuevas Poblaciones de Sierra Morena y Fuero de sus pobladores", Novisima Recopilación, Libro VII, Título XXII, Ley $\mid l l$ y IV.

4 Alcazar Molina, C. La colonización alemana de Sierra Morena. Madrid 1926, pág. 3.

- Capel Margarito, M. La Carolina, capital de las Nuevas Poblaciones. Jaén 1970, pág. 176. A propósito de estas acusaciones, Capel aporta varios documentos que revelan la falsedad de las acusaciones vertidas hacia Olavide. En este sentido, ver las declaraciones de jefes de los Regimientos subdelegados, jueces, etc... en Capel Margarito, M., op. cit., págs. 176-183. Por otra parte conviene recordar que una epidemia de fiebres «tercianas", hizo estragos en Andalucia en el verano de 1768, motivando seguramente retrasos en la obra colonizadora. 
Ante la gravedad de las denuncias, se convocó la reunión de una junta constituida por cuatro consejeros y presidida por Aranda que acordó el envío de don Pedro Pérez Valiente en visita de inspección, labor que se prorrogó desde el 24 de abril hasta el 24 de agosto de 1769.

Durante estos meses Pérez Valiente, que habia sido catedrático y rector de la Universidad de Granada, asumió la Superintendencia General de las Nuevas Poblaciones de forma provisional ${ }^{6}$, mientras Olavide se retiraba a EI Viso para no estorbar su inspección ${ }^{7}$.

Durante su visita se ordenó la realización de una relación completa de todos los empleados sitos en las Nuevas Poblaciones de Sierra Morena, señalando las funciones que desempeñaban en sus diferentes destinos, así como los emolumentos que percibian por ello ${ }^{8}$.

De dicha relación localizada en la Sección de Manuscritos de la Biblioteca Nacional de Madrid, se desprende que el mayor aparato administrativo se encontraba ya ubicado en La Peñuela como capital de las Nuevas Poblaciones de Sierra Morena y cuyo nombre mantuvo hasta 1770 en que pasó a denominarse ya definitivamente, La Carolina.

De la administración de La Peñuela se ocupaban:

$\begin{array}{ll}1 & \text { contador } \\ 1 & \text { tesorero } \\ 1 & \text { asesor general } \\ 1 & \text { capellán mayor } \\ 1 & \text { habilitado general } \\ 1 & \text { secretario } \\ 3 & \text { oficiales de la secretaria } \\ 4 & \text { oficiales de la contaduria } \\ 1 & \text { delineante } \\ 1 & \text { ingeniero }\end{array}$

1 contador

1 tesorero

1 asesor general

1 capellán mayor

1 habilitado general

1 secretario

3 oficiales de la secretaría

1 delineante

En las demás poblaciones de Sierra Morena, el aparato administrativo era mucho más simple. Así, en Carboneros habia un director, un guardalmacén y cuatro inspectores; en Guarromán, un director, un habilitado,

\footnotetext{
${ }^{6}$ «... pase a las nuevas colonias un sujeto de entereza, inteligencia y autoridad, que en calidad de visitador, reasuma la jurisdicción y facultades del superintendente de las nuevas poblaciones y de todos los subalternos, se instruya y averigüe por el medio que juzgare más oportuno y sin formalidad de proceso, del estado de las colonias..." (Archivo Histórico Nacional (en adelante AHN), Gobernación, leg. 328, n. ${ }^{\circ} 23$ ).

7 Capel Margarito, M., op. cit., pág. 186.

${ }^{8}$ Biblioteca Nacional de Madrid (en adelante BNM), Mss. 18745, exp. 58.
} 
un capellán, un médico y cirujano, un maestro de primeras letras, un guardalmacén y cuatro inspectores; en Rumblar, un director, un capellán, un habilitado, un cirujano y dos inspectores; en Arquillos, un director, un capellán, un habilitado, un cirujano, un maestro de primeras letras y tres inspectores; en Venta de Santos, un director, un habilitado, un capellán, un cirujano y administrador de hospital y dos inspectores; en Aldeaquemada, un director, un capellán, un cirujano, un habilitado y dos inspectores; en Santa Elena, dos directores (uno en Santa Elena y otro en Miranda), un capellán, un maestro de primeras letras, un cirujano, un habilitado y tres inspectores.

Las funciones de todos ellos aparecían perfectamente delimitadas. Así el asesor general entendía en todas las causas civiles y criminales y de policía de las poblaciones.

El habilitado general era el suministrador de prest y pan a los colonos, según los libros familiares aportados por la superintendencia. Para ello se tenian muy en cuenta las altas y bajas en los nacimientos, los aumentos de edad, muertos, desertores, etc... noticias todas ellas proporcionadas por inspectores y comandantes. Asimismo, el habilitado general se encargaba del pago mensual de los sueldos de los habilitados particulares, inspectores, tropa auxiliar y gañanes destinados a la realización de los trabajos comunes en los distintos departamentos.

El capellán mayor ejercia las funciones eclesiásticas de la colonia y estaba por encima de los demás capellanes particulares de cada zona quienes le informaban de las novedades, es decir, nacidos, difuntos, casamientos, etc..., pasando dicha información a la Secretaria donde se confrontaba con la facilitada por los inspectores, para llegar posteriormente a la contaduría y habilitación general.

Los ayudas de capellán asistían las iglesias de La Peñuela y Carboneros (en esta última colonia no habia capellán propio), administrando los Sacramentos en esos puntos.

Delineante e ingeniero se encargaban de la demarcación y delimitación de los terrenos «reduciéndolos a cuadrilongos perfectos que son los que forman la uniformidad y simetrias de las suertes»" ${ }^{9}$.

El médico y el cirujano atendian el hospital y notificaban a la superintendencia las altas y bajas correspondientes.

Los guardalmacenes eran los depositarios de todos los útiles y efectos que entraban en la colonia por compra o remisión.

${ }^{9}$ Ibidem. 
Las nuevas poblaciones de Sierra Morena bajo la superintendencia ...

Los maestros de primeras letras eran los responsables de la enseñanza de los hijos de los colonos.

Los dos maestros mayores de obras recorrian y examinaban diariamente el estado y progreso de las obras.

El inspector general estaba obligado a visitar los diferentes departamentos con el fin de vigilar el correcto cumplimiento de sus obligaciones por parte de los inspectores de las distintas zonas. Cada uno de ellos tenía a su cargo de 27 a 30 suertes o familias y para garantizar su gestión se creó una «Instrucción» para inspectores en $1768{ }^{10}$. Estos inspectores debian velar por la realización de los trabajos señalados dentro de su departamento, vigilando a sus individuos para evitar vicios y relajaciones. Estaban obligados a residir en sus respectivas zonas no pudiendo abandonarlas salvo en los días festivos, señalados para presentarse a sus comandantes correspondientes y participarles las novedades acontecidas en sus departamentos. Si algún individuo caía enfermo, el inspector debía enviarlo al hospital con una cédula que comprendiera los datos correspondientes: departamento, nombre del enfermo, familia, número de suerte, etc...

Los directores dirigian las obras y operaciones en los diferentes puntos con los caudales proporcionados por la superintendencia. A finales de cada mes estaban obligados a presentar los oportunos justificantes de los gastos realizados.

Por último, los habilitados particulares se ocupaban de la contabilidad, especialmente del pan y prest, juntamente con los inspectores de cada zona.

Aparte de estos oficios específicos de las distintas colonias, existian otros generales, comunes a todas ellas. Asi habia dos capellanes, uno alemán y otro español que se ocupaban del consuelo y asistencia de los enfermos del hospital. También cuatro inspectores llamados supernumerarios que se encargaban de supervisar la labor de los demás inspectores, relevando a aquellos que no cumplieran con su obligación. Igualmente, habia una tropa común a todos los departamentos, compuesta por 29 cabos y 58 soldados para auxiliar a los inspectores. Por su parte, dos interventores se encargaban de la distribución del caudal necesario para la continuación de las obras, satisfaciendo jornales y proporcionando materiales.

10 Lera Garcia, R., "Conflictividad social en las Nuevas Poblaciones de Sierra Morena 1767-70», Carlos III y las "Nuevas Poblaciones» (Actas del II Congreso-Histórico. La Carolina 1986), tomo III. Córdoba 1988, págs. 43-46. 
Con motivo de la visita de Pérez Valiente, además de la preparación del cuadro administrativo existente en las distintas colonias de Sierra Morena y cuyas funciones acabamos de esbozar, se elaboró un estado de cuentas general para evaluar el costo de las Nuevas Poblaciones en este periodo inicial de funcionamiento.

Respecto a Sierra Morena, que es el tema que nos ocupa, habian entrado en la pagaduría general de La Peñuela, desde el mes de agosto de 1767 hasta el mes de abril de 1769, 7.087.734 reales de vellón entre los que se incluian, entre otras, las rentas provinciales de Jaén, las del tabaco y salinas de Jaén así como las del tabaco de Granada. Por su parte, la data, originada de legitimar libramientos dados por la superintendencia e intervenidos por la contaduria, alcanzaba la cifra de 6.932 .348 reales de vellón. Dicha data incluía los salarios de los empleados, el prest de los colonos, el valor de las casas ya construidas, útiles y herramientas, mantas y jergones, gastos de hospital y capilla, etc...

Asi pues quedaban 155.385 reales de vellón para continuar con el peso de la superintendencia ${ }^{11}$, sin contar con los efectos de los regulares expulsados, especialmente granos, ganados, ornamentos litúrgicos ${ }^{12}$ y aperos de labranza, destinados a la Nuevas Poblaciones. Precisamente, en abril de 1769, coincidiendo con la visita de Pérez Valiente, se empezó a llevar a cabo una evaluación ajustada de los enseres de los jesuitas que habian entrado en las colonias. Según reza en el propio expediente:

«Luego que la contaduría acabe de sacar los valores, se formará un estado gerieral por clases que comprenda la entrada, inversión y existencia, operación que no puede practicarse ni tener lugar al presente porque tanto los cargos como las datas están en especies que necesitan un estado mucho más extensivo que el de la entrada y salida de caudal. Pero por un cálculo prudencial que se ha hecho por mayor, se deduce que los efectos consumidos y repartidos hasta el 24 de abril, apenas ascenderán a quinientos mil reales de vellón y los restantes están en física y real existencia a disposición del señor Valiente en los respectivos almacenes» ${ }^{13}$.

BNM, Mss. 18745, exp. 58.

12. En este sentido ver PALAcios ALCALDE, M., "Mobiliario litúrgico distribuido a las Iglesias de las Nuevas Poblaciones de Sierra Morena", Carlos III y las "Nuevas Poblaciones" (Actas del Il Congreso-Histórico. La Carolina 1986), tomo IIl. Córdoba 1988, págs. 189-213.

13 BNM, Mss. 18745, exp. 58. Ver Gomez Martinez, E., «Bienes procedentes del desaparecido convento-colegio de jesuitas en Andújar, que se enviaron a La Peñuela para la fundación de las Nuevas Poblaciones de Sierra Morena", Comunicación presentada al IV Congreso-Histórico de las Nuevas Poblaciones. La Carolina 1990. 
En este marco administrativo y económico se desenvolvía la vida de los colonos a la llegada de don Pedro Pérez Valiente ${ }^{14}$. El 11 de mayo de 1769 habia, entre las poblaciones de Sierra Morena y las de Andalucia, 5.703 colonos $^{15}$, muchos de los cuales no habían recibido aún las 50 fanegas de tierra prometida ${ }^{16}$.

Por otra parte, la construcción de sus viviendas se hacía de forma bastante anómala en cuanto a calidad, entre otras cosas por la falta de agua y de materias primas. En este sentido, según Vázquez Lesmes, la zona de Sierra Morena comprendida entre Constantina y Cazalla de la Sierra, la Sierra de Segura y Sierra de Yeguas, se convirtió en abastecedora importante de maderas para la techumbre de las viviendas, mientras que la cal, tejas y otros materiales se producian en una serie de hornos que utilizaban como materia prima, la encontrada en los terrenos cercanos a las edificaciones ${ }^{17}$.

Además, las viviendas se habian ido construyendo de forma dispersa según la tesis de Olavide, para obtener una mayor cercania entre la vivienda y el lugar de trabajo con el fin de lograr los mayores rendimientos agrícolas de los nuevos pobladores. Esta idea triunfó pese a la opinión contraria del ingeniero Dernaux ${ }^{18}$, partidario de agrupar las viviendas en pequeñas aldeas para asegurar la sociabilidad e integración de los colonos extranjeros ${ }^{19}$.

El pan constituía, junto con el prest, la remuneración diaria de los colonos. De la elaboración y distribución del pan se encargaban algunos asentistas, que en busca de sacar la mayor rentabilidad, no dudaron en rebajar tanto la calidad como el peso del producto. En cuanto al prest o paga en metálico, contribuía a cubrir el resto de necesidades de los colonos, es decir alimentos, vestido, etc... Cada colono mayor de dieciséis

${ }^{14}$ Las relaciones sociales y las condiciones de vida de los colonos en Lera Garcia, R., op. cit., págs. 41-55.

15 AHN, Gobernación, leg. 328, n. ${ }^{\circ} 23$.

16 Sánchez Martinez, C. y Hita Fernández, J. J., "Las suertes y las colonias de Sierra Morena en los levantamientos topográficos de don José de Ampudia y Valdés», Carlos II/ y las «Nuevas Poblaciones» (Actas del II Congreso-Histórico. La Carolina 1986), tomo I. Córdoba 1988, pág. 178.

"VAZQUEz LESMES, J. R., La ilustración y el proceso colonizador en la campiña cordobesa. Córdoba 1979, pág. 28.

${ }^{18}$ Simón Dernaux, capitán de ingenieros nombrado por S. Mg. para realizar los planos de la colonia de La Carlota, fue nombrado director de Fuente Palmera (GARCía Cano, M. ${ }^{2}$ I., "La burocracia de las Nuevas Poblaciones: aspectos institucionales y problemas económicos del régimen foral y constitucional», Carlos $1 / 1$ y las "Nuevas Poblaciones" (Actas del II Congreso-Histórico. L.a Carolina 1986), tomo III, Córdoba 1988, pág. 17.

19 Lera Garcia, R., op. cit., pág. 50. 
años percibia un real diario y una ración de pan. Entre diez y dieciséis años recibian $6 / 4$ de real e igual ración de pan, mientras que los menores de diez años obtenian $4 / 4$ de real y media ración de pan ${ }^{20}$.

Concidiendo con la visita de Pérez Valiente, varias familias españolas de jornaleros solicitaron su conversión en colonos. La mayor parte habian estado trabajando en las obras públicas de las colonias por espacio de varios meses con un jornal de cuatro reales diarios, descontando los domingos, días festivos y los días de lluvia en que no se percibía jornal.

Obviamente, como colonos sus ganancias eran superiores puesto que no sólo cobraban los trabajadores de cada familia sino cada miembro de la unidad familiar. Además se les proporcionaba mantas, jergones, herramientas, casa, dos vacas, arado, cinco cabras, cinco ovejas, cinco gallinas, un gallo y una cerda, según lo estipulado en el Fuero de Población.

En vista de las ganancias que se originaban en estas familias convertidas de jornaleros en colonos, muchas otras familias, originarias sobre todo de Cataluña y Valencia, solicitaron su ingreso en las Nuevas Poblaciones como colonos. La superintendencia juzgó positivo este ingreso dadas las bajas producidas en muchas familias de alemanes por muerte y deserción ${ }^{21}$. Además, el propio Fuero de Población fijaba la presencia de colonos hispanos: «en cada lugar puede ser útil admitir desde luego, dos o más vecinos españoles especialmente de Murcia, Valencia, Cataluña, Aragón, Navarra y toda la costa septentrional de Galicia, Asturias, Montañas, Vizcaya y Guipúzcoa, para que se reunan con los naturales haciendo matrimonio reciproco, quedando sujetos a las mismas reglas que los colonos extranjeros" 22 .

De este modo las familias españolas suplirian a las extranjeras recogiendo a sus huérfanos e inculcándoles la lengua, labores agricolas... Sin embargo, se acordó realizar la admisión sin demasiados costos para la superintendencia combinando el aumento de la colonia con el menor costo posible. Nació asi en 1769 la figura del medio colono. Cada matrimonio con un hijo recibia siete reales semanales; los matrimonios con dos o tres hijos, diez reales y las familias con más de cuatro hijos, 12 reales a la semana ${ }^{23}$. Además se les proporcionaban raciones de pan semejantes a

20 BNM, Mss. 18745, exp. 58.

${ }^{21}$ Se crearon incluso guardias con la misión de capturar desertores. Los castigos eran variados: suspensión de la entrega de pan y prest, trabajo durante varias jornadas en los equipos comunitarios, argolla o vergüenza pública, cárcel, remisión del colono al ejército o a la marina... (Lera Garcia, R., op. cit, pág. 53).

22 "Reglas para las Nuevas Poblaciones de Sierra Morena y Fuero de sus pobladores", Novisima Recopilación, Libro VII, Título XXII, Ley III, articulo 72.

${ }^{23}$ BNM, Mss. 18745, exp. 58. 
las del resto de los colonos según sus edades asi como herramientas, jergones y un par de vacas cuando estuvieran en situación de manteneilas.

Sin embargo, los medios colonos debian ocuparse de la construcción de su casa y de la adquisición de ganados. A pesar de todo, su situación, sin ser equiparable a la de los colonos ya establecidos, era sustancialmente mejor que la anterior como jornaleros.

A la vista de toda esta situación político-económica, don Pedro Pérez Valiente emitió su dictamen ${ }^{24}$. Sobre todo basó su visita en la realización de un examen de las colonias, poniéndolo en relación con lo establecido en el Fuero de Población, con el fin de dictaminar si los artículos del mismo resultaban modificados por el auténtico statuo quo vigente.

Así, Pérez Valiente se quejaba de la llegada de escasos labradores y en cambio, de muchos desertores franceses. Además muchos de los colonos eran protestantes.

Por otra parte mencionaba el excesivo número de empleados existente en las Nuevas Poblaciones, los cuales, consumian 625.837 reales de vellón. En este sentido conviene recordar que sólo en las colonias de Sierra Morena, los sueldos de los empleados ascendian a 455.037 reales de vellón al año ${ }^{25}$. Hecha la relación de oficios existentes en las colonias con los nombres propios de sus ocupantes, Pérez Valiente realizó una crítica pormenorizada, tanto positiva como negativa según los casos, de los individuos que ostentaban los principales cargos, tanto en Sierra Morena como en Andalucía.

También criticaba la construcción excesivamente acelerada y dispersa de las viviendas, mostrándose partidario de dividir las colonias en feligresias compuestas por tres o cuatro pequeñas aldeas de 15 a 30 vecinos cada una y ello no se había cumplido:

«V.M. quiso hacer de estos colonos unos vasallos racionales y sociables y con la situación de las casas en sitios dispersos y distantes, vivirán como brutos, sin comercio, sin instrucción suya ni de sus hijos, pues aunque hay algunas escuelas, no pueden enviarlos a ellas ni es posible que se instruyan en los principios de la religión, ni en el idioma» ${ }^{26}$.

24 AHN, Gobernación, leg. 328, n.223.

25 BNM, Mss. 18745, exp. 58.

${ }^{26}$ AHN, Gobernación, leg. 328, n. 23. 
Otro problema era la falta de planos y de una correcta demarcación, lo cual habia ocasionado que muchos colonos no dispusieran aún de las 50 fanegas de tierra prometidas. Y lo que era más importante, la ignorancia de los limites concretos de las Nuevas Poblaciones repercutia en agravios por parte de los pueblos circunvecinos que se veian desposeidos, en muchos casos, de sus dehesas, baldios, cañadas, abrevaderos... Ciñéndonos al caso concreto de Sierra Morena, que es el que nos ocupa, Pérez Valiente aconsejaba que La Peñuela se mantuviera entre otras dos aldeas, Venta de Linares y otra de nueva construcción. Santa Elena debía reducirse a un pequeño lugar reedificado alrededor de la ermita. Guarromán, Carboneros y otro pueblo de nueva construcción, podian formar otra feligresia. Las poblaciones de Rumblar, Magaña y Aldeaquemada debian ser abandonadas «por lo estéril y mal sano del terreno». Arquillos, Porrosillos y Venta de Santos, por el contrario, debian conservarse.

En definitiva, Pérez Valiente consideró que casi todos los articulos del Fuero de Población se veian atacados por la realidad imperante:

«En resumen de todo para descargo de su conciencia, representa el visitador a V.M. que ha notado por sus propias observaciones, por los informes de los ocho oficiales suizos que le dio el conde de Aranda, por el de los capellanes de las poblaciones, el de personas fidedignas de los pueblos comarcanos, ..., por el clamor general y uniforme de los colonos de todas partes y por una multitud de documentos..., que el superintendente y subdelegados no han observado la Cédula de Población en sus más principales puntos, de que se han seguido crecidisimos dispendios del Real Erario, grandes perjuicios a los pueblos antiguos, especialmente de la Andalucia, y ningún beneficio ni arreglo a los colonos, antes si, gravisimos daños en lo espiritual y temporal» ${ }^{27}$.

En definitiva, el resultado final de la visita de inspección cursada por Pedro Pérez Valiente a las Nuevas Poblaciones fue una nueva Instrucción para el gobierno de las colonias que empezó a regir el 6 de julio de 1770 bajo la superintendecia, de nuevo, de Pablo de Olavide ${ }^{28}$.

\footnotetext{
lbidem.

28 Ibidem. Dicha instrucción aparece estudiada por Garcia Cano, M ${ }^{*}$ 1., op. cit., págs. 19 y 20; y desde el punto de vista de los colonos por Lera Garcia, R., op. cit., pág. 46.
} 


\section{APÉNDICE DOCUMENTAL}

RELACIÓN DE TODOS LOS EMPLEADOS DE LAS NUEVAS POBLACIONES DE SIERRA MORENA, REALIZADA POR ORDEN DE DON PEDRO PÉREZ VALIENTE

LA PEÑUELA

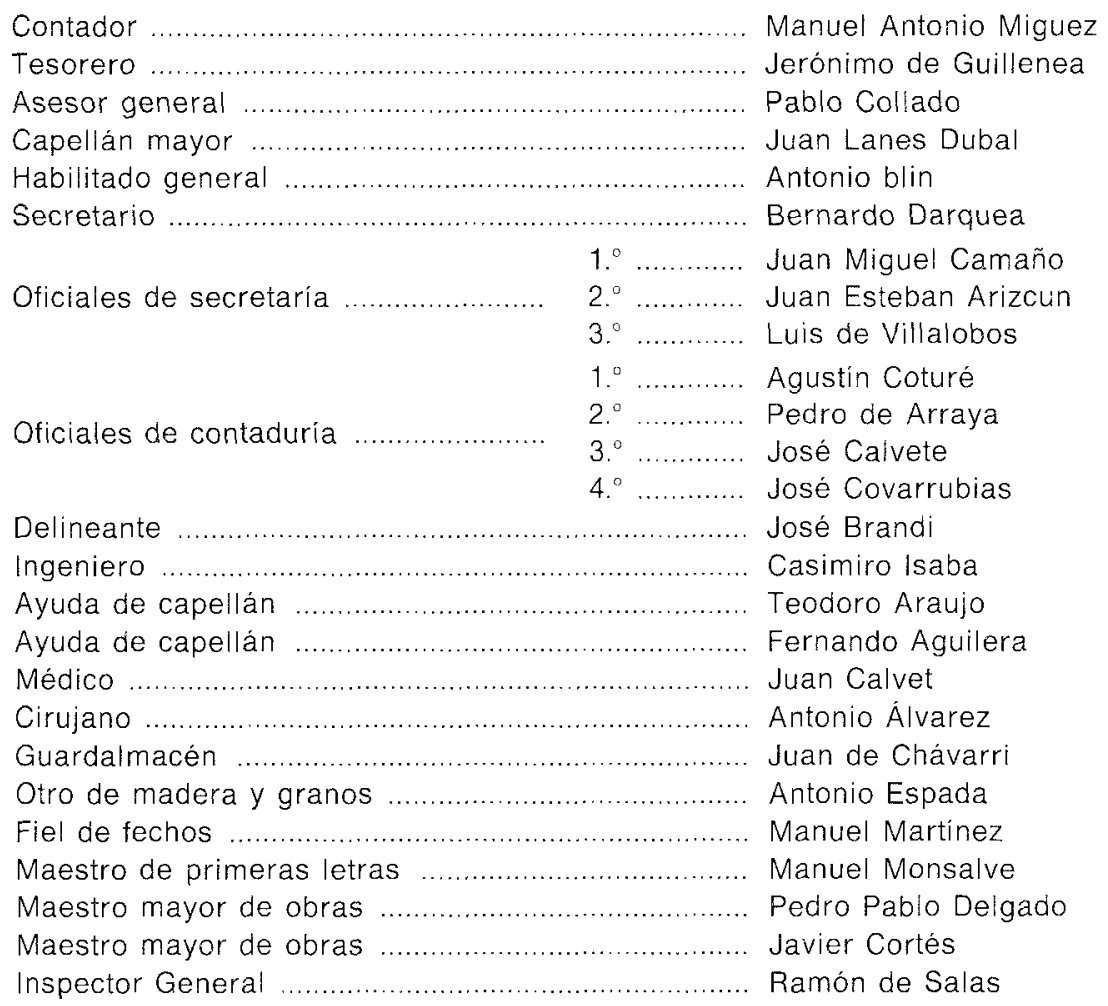




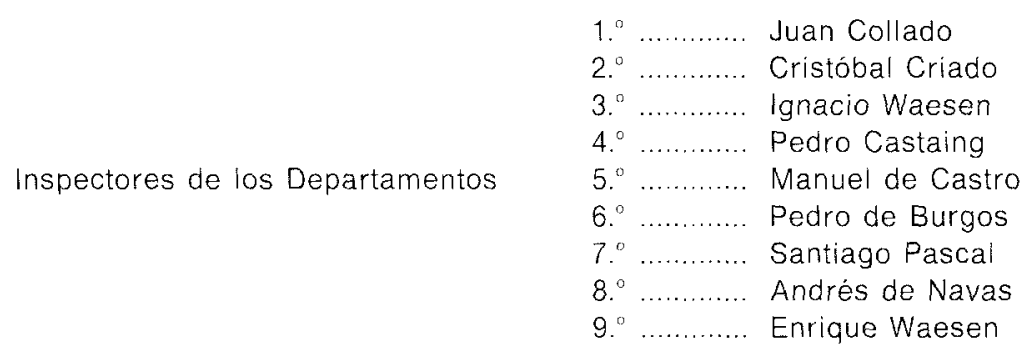

CARBONEROS

Director Juan Bautista Navarro

Guardalmacén Vicente Rico

Inspectores

1. Miguel Garrido

2. ............ Ramón Espada

3. Joaquin de Torres

4.

Santiago Vida!

\section{GUARROMÁN}

Director

Habilitado

Capeilán

Médico y cirujano

Maestro de primeras letras

Guardalmacén

Inspectores

\section{(a)}

$1 .{ }^{\circ}$

$2{ }^{\circ}$

$3{ }^{\circ}$

$4 .^{\circ}$
Álvaro de Ortega

Pedro Olave

Diego Ortega José Alviceti Pedro Monsalve Ignacio Gómez Francisco Segura Andrés Mosquera Alonso Segura Francisco Andaya

RUMBLAR

Director

Capellán

Habilitado

Cirujano

Inspectores
Juan Bruguieros Francisco de la Cova José Baliesteros Francisco Villamia Francisco Madero

1. ${ }^{\circ}$ 2. José Díaz Madero 


\section{ARQUILLOS}

\begin{tabular}{|c|c|c|}
\hline Director & & Ignacio Flores \\
\hline Capellán & & José Miguel Márquez \\
\hline 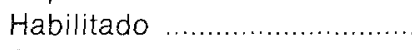 & & Juan Fabro \\
\hline 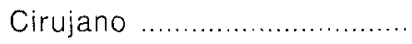 & & Antonio Langenbein \\
\hline Maestro de primeras letras & & José Rueda \\
\hline & 1.0 & Antonio del Pino \\
\hline Inspectores & $2 .{ }^{\circ}$ & Dionisio Tartabe \\
\hline & 3. & Francisco Echavy \\
\hline
\end{tabular}

VENTA DE SANTOS

Director

Mariano Aranguren

Habilitado Juan Matías Aguirre

Capellán Juan Martínez Lozano

Cirujano y administrador de hospital Marcos Agustín Escobar Inspectores $1 .{ }^{\circ}$ Francisco Escobar Ignacio Casado

\section{ALDEAQUEMADA}

Director Agustin Genestet

Capellán Francisco Abad Mejía

Cirujano Sebastián Paulini

Habilitado Vicente Espinosa

Inspectores Alejandro Giraldeli Juan Poveda

\section{SANTA ELENA}

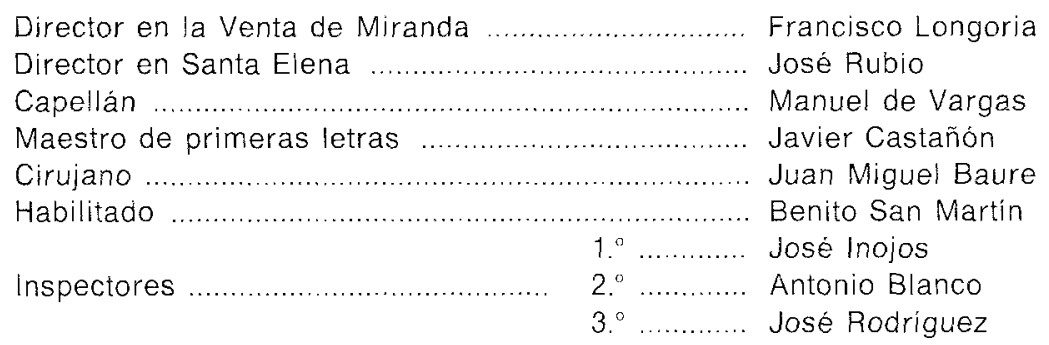




\section{CARGOS COMUNES}

Hospital General

Capellán alemán Matias Gokler

Capellán español Juan Sánchez Colado

Supernumerarios

Comandante José Coelio

$1 . \circ$ Rafael Oroño

Inspectores

2. José Rico

$3 .{ }^{\circ}$ José Yllera

Tropa

Para los 29 Departamentos

29 cabos

58 soldados

Interventores

$1 .{ }^{\circ}$

Bernardo Espinosa

$2 .{ }^{\circ}$ Manuel de los Ríos 